\title{
PROTEIN GELS: A MINI REVIEW
}

\author{
Silvana D. Harikedua ${ }^{1}$ \\ ${ }^{1)}$ Staf pengajar pada Program Studi Teknologi Hasil Perikanan, \\ Fakultas Perikanan dan Ilmu Kelautan, Universitas Sam Ratulangi, \\ Jl. Kampus UNSRAT Bahu, Kec. Malalayang, Manado, 95115. \\ Email: silvana.harikedua@unsrat.ac.id
}

\begin{abstract}
The use of gelatin as food additive for gelling properties was discussed in this review. Three products (i.e. gel dessert, yoghurt, and surimi) were selected as the main focus of this mini review since they characterized 3 different protein gelation system. The mechanism of gelatin gelation in water system was described by gel dessert, the gelation of casein in dairy product was presented by yoghurt, and the gelation of sarcoplasmic protein in meat system was exemplify by surimi. All in all, the mechanism of gelation mainly contributed by the networking of protein-protein which is strengthen by the intermolecular bond and intramolecular bond.
\end{abstract}

Keywords: protein, gelatin, gel dessert, yoghurt, surimi.

\section{INTRODUCTION}

Gelatin is widely used in various food products. Commercial gelatin is produced from pig skin or cow skins and bones (Karim \& Bhat 2008). However, issue arises about the use of mammalian gelatin due to mad cow disease cases, as well as vegetarian, halal and kosher related markets. Fisheries by-products might be an alternative solution to this issue. Documented study indicated that fish gelatin can be used as an emulsifier (Surh et al. 2006) and in water gels dessert (Zhou \& Regenstein 2007). In the past decades, a number of articles have been published relating to gelatin functional properties and its role as food additive, production of gelatin from various fish by-products, the comparison between gelatin and plant hydrocolloid, and the synergism between plant hydrocolloid and gelatin in food products. In general, gelatin in food products can be used as an emulsifying, gelling, foaming, water binding, film forming, and clarifying agent (Karim \& Bhat 2008). Moreover, Mariod and Adam (2013) noted that the grade of gelatin depends on its physical properties such as viscosity and gel strength. Miscellaneous function of gelatin makes it interesting to explore. However, this review will only focus on the mechanism of gelatin gelation in gel dessert and the mechanism of gelatin as a gel enhancer on yoghurt and surimi. These 3 products are selected because each of them represents a different protein gelatin system. Gel dessert describes the mechanism of gelatin gelation in water system, yoghurt correspond to gelation of casein in dairy based product, and surimi denote the gelation of sarcoplasmic protein in meat system. This review also will highlight the distinctive characteristics between mammalian gelatin and fish gelatin and their impacts to the above listed products.

\section{Gel Dessert}

Gelatin can be described as a "pure, tasteless, odorless, transparent, brittle, glasslike solid, very faint yellow to amber in color" (Djagny et al. 2001). Gelatin forms gels similar to carbohydrates by forming a micro-structural network (Mariod \& Adam, 2013). The most common use of gelatin is as thermally reversible gelling properties such as in water desserts (Karim \& Bhat, 2008). It has unique properties since at concentrations as low as $1.0 \%$ it will form a thermo-reversible gel. The gel can alter to a solution at 30 to $40{ }^{\circ} \mathrm{C}$ so that final product is likely melt in the mouth (Morimura et al., 2002 cited in Mariod and Adams, 2013). Pang et al. (2014) reported that the elasticity of gelatin gels was significantly affected by the concentration of gelatin. Higher gelatin concentrations generate stronger gel, higher gelling and melting temperatures.

Djagny et al. (2001) suggested that "small sections of a number of gelatin molecules might unite to form crystallites, offering a structure of a highly ramified three-dimensional network capable of immobilizing the liquid". According 
to Mariod and Adam (2013) "gelatin will swell upon contact with cold water forming large visible swollen particles, when heated above the melting point, the hydrated gelatin will rupture and go into solution and form a gel upon cooling". McWilliams (2001) noted that "the formation of a gelatin gel is endothermic and occurs gradually as the energy of the system dissipates" (cited in Mariod \& Adam 2013). Furthermore, Nishimoto et al. (2005) suggested that there is a "random coiled helix reversion" of the amino acid from different polypeptide chains that act as potential junction zones, so that during cooling perform a helical conformation resulting in the three-dimensional gel (cited in Mariod \& Adams, 2013).

Principal difference between fish and mammalian gelatin is the content of the amino acids proline and hydroxyprolyne (Haug et al.2004). Fish gelatin showed lower concentrations of the amino acids proline and hydroxyproline. Therefore, fish gelatins might characterize low gel modulus, low gelling and melting temperature (Haug et al., 2004). This evidence was supported by Zhou et al. (2006) which reported that the hydroxyproline concentration of Alaska Pollock and Tilapia gelatin was lower than that of pork (Table 1). Alaska Pollock and Tilapia contained $7.3 \%$ and $10.6 \%$ of hydroxyproline, respectively, while pork gelatin with low and high bloom have hydroxyproline content ranging from 13.1 to $13.3 \%$.

Table 1. Chemical and physicochemical properties of gelatins (mean \pm standard deviation)

\begin{tabular}{lrrrr}
\hline Property & AG & TG & PG1 & PG2 \\
\hline Hydroxyproline content $(\%)$ & 7.3 & 10.6 & 13.3 & 13.1 \\
& \pm 0.3 & \pm 0.2 & \pm 0.2 & \pm 0.3 \\
Bloom strength (Bloom) & 98 & 273 & 110 & 240 \\
& \pm 2.0 & \pm 4.0 & \pm 3.0 & \pm 5.0 \\
Gel melting temperatures $\left({ }^{\circ} \mathrm{C}\right)$ & 21.2 & 25.4 & 27.5 & 31.2 \\
& \pm 0.2 & \pm 0.2 & \pm 0.3 & \pm 0.1 \\
Viscosity (mP) & 120 & 38 & 22 & 47 \\
& \pm 2.0 & \pm 1.0 & \pm 1.0 & \pm 1.0 \\
\hline
\end{tabular}

$\mathrm{AG}=$ Alaska Pollock gelatin; $\mathrm{TG}=$ tilapia gelatin, $\mathrm{PG} 1=$ pork gelatin with low bloom value; PG2 = pork gelatin with high bloom value. Source: Zhou et al.(2006)

The most crucial factor that should be maintained in the formulation and development of gelatin dessert is the $\mathrm{pH}$. Djagny et al. (2001) suggested that $\mathrm{pH}$ should be maintained between 3.0 and 3.5 for "palatable tartness". Zhou and Regenstein (2007) observed that gel strength of the fish gelatins decreased rapidly below $\mathrm{pH}$ 4.0. This idea was supported by
Ninan et al. (2011) which reported that water gel desserts prepared from fish gelatin at $\mathrm{pH}$ ranging from 3.6 to 3.8 showed low melting point and low gel strength.

Other ingredients (i.e. sucrose and sodium chloride) used in the formulation of desserts can affect gel strengths and melting point of gelatin water dessert (Ninan et al., 2011). In normal conditions, fish gelatin also showed a lower melting point and need a longer time to reach a constant value than pork gelatins. Adding sodium chloride seems to reduce fish gelatin gel strength and melting point when compared to pork gelatin. However, their gel strength and melting point will increase due to the addition of sucrose (Djagny et al., 2001).

Additionally, from the sensory evaluation of water gel dessert, Choi and Regenstein (2000) concluded that fish gelatins had less off odor and better aroma than pork gelatins. The lower melting point of fish gelatins in water gel dessert boost flavor release, fruit aroma and melt rate. This evidence also supported by Ninan et al. (2011) which demonstrated that water gel dessert using gelatins extracted from cultured freshwater carp and grass carp skin gelatin has a lower detectable odor (1.5-1.6) than mammalian gelatin (2.1-2.3). In general, fish gelatin can be considered as the alternative source to replace mammalian gelatin as water gel dessert ingredient.

\section{Yoghurt}

Yoghurt is a fermented dairy product which is treated with lactic acid bacteria. It is a semisolid product, sweetened and flavored with fruit flavor characteristics. There are three major types of yoghurt is drinking, set and stirred yoghurt (Karam et al., 2013). Lee and Lucey (2010) documented 5 keys steps of processing yoghurt i.e "standardization of milk (fat and protein content), homogenization, milk heat treatment, incubation/fermentation, cooling and storage". Likewise, texture of yoghurt is affected by temperature and time of heat treatment, type and amount of starter bacteria, temperature of fermentation, storage conditions and protein composition of the milk (Karam et al., 2013).

The gelation mechanism in yoghurt processing is dominantly contributed by casein. Initial process is including homogenization of milk. During homogenization, caseins and whey proteins create new smaller fat globules which 
intensified the number of possible structurebuilding components in yoghurt. Furthermore, heating milk at a temperature $85^{\circ} \mathrm{C}$ for 30 minutes or $90-95^{\circ} \mathrm{C}$ for 5 minutes will denature whey proteins and affect the complex configuration of whey protein-whey protein or whey protein-casein micelles which initiate gelation process (Lee \& Lucey 2010; Karam et al. 2013). This process might involve $\kappa-\mathrm{CN}$, hydrophobic interactions and intermolecular disulphide bonds (Haque \& Kinsella 1988; Singh 1995 cited in Lucey 2002). Cooling at the starter culture growth temperature $\left(40-45^{\circ} \mathrm{C}\right)$ was applied to milk after heat treatment. Two strains of lactic acid bacteria (LAB), i.e. Streptococcus subsp. thermophilus and Lactobacillus delbrueckii subsp. bulgaricus were commonly used in yogurt processing. Fermentation process by LAB will alter lactose into lactic acid and decline the $\mathrm{pH}$ of milk.

Figure 1 showed typical $\mathrm{pH}$ profiles during the fermentation of yoghurt. In essence, there are $3 \mathrm{pH}$ regions which contributed to the formation of acid milk gels (Lee \& Lucey, 2010). First region occurs when milk pH (6.7) decline to 6.0. As the net negative charge on the casein micelles reduce, an electrostatic repulsion decrease, but the size of the casein micelles is mostly unchanged. As the $\mathrm{pH}$ of milk drop further from $\mathrm{pH} 6.0$ to 5.0 (second region), the net negative charge on casein micelles decline significantly, K-casein "hairs" shrink, electrostatic repulsion and steric stabilization decreased, and it changes the stability of casein micelles compared to casein structure in the original milk. At this point $(\mathrm{pH}$ $\leq 6.0$ ), the fermentation process increases the rate of colloidal calcium phosphate (CCP) solubilization, lessens the internal structure of casein micelles, and improves the electrostatic repulsion between the visible phosphoserine residues.

Finally, as the $\mathrm{pH}$ drop close to the isoelectric point of casein $(\mathrm{pH} 4.6)$, the net negative charge on casein decreased results in the reduction of the electrostatic repulsion between casein molecules. On the contrary, casein-casein interaction increase attributable to the increased of hydrophobic and electrostatic charge interactions (Horne 1998 cited in Lee \& Lucey, 2010). Also, the acidification process leads to formation of a three dimensional network consisting of casein cluster, chains and strands (Karam et al., 2013).
Furthermore, gelatin can be used as a stabilizer in yoghurt. Adding stabilizer in yoghurt will enhance the proper yoghurt properties such as texture, mouthfeel, appearance, viscosity, and to prevent the whey separation (Lee \& Lucey, 2010). The interaction between gelatin and casein in yoghurt production might develop a sturdy three dimensional network which retain syneresis and create stable yoghurt texture (Fiszman et al.1999; Fiszman and Salvador, 1999 cited in Ares et al., 2007).

Other study by Ares et al. (2007) on the effect of starch and gelatin on stirred yoghurt showed that sensory viscosity, ropiness, mouthfeel, and creaminess is improved after adding gelatin. If we compared gelatin samples with control, it showed that gelatin based products showed a higher pseudoplastic behavior and a higher apparent viscosity. Gelatin also showed effectiveness in preventing syneresis than starch. The addition of $6 \mathrm{mg} / \mathrm{g}$ of gelatin prevented the occurrence of syneresis, the addition of starch only reduced it. They concluded that $6 \mathrm{mg} / \mathrm{g}$ gelatin could be reasonable concentration to use in the manufacture of low fat yoghurts.

Moreover, Pang et al. (2014) study the effect of whey protein isolate (WPI), milk protein concentrate (MPC) and skim milk powder (SMP) to gelatin gels. They reported that milk protein concentrate (MPC) and skim milk powder (SMP) heighten the textural properties of gelatin gels. The textural properties depend on the concentration of milk. Adding all milk powders to high gelatin concentration $(5.0 \%)$ resulting in the increased of the hardness of gelatin gels. It is likely that the gelation mechanism in yoghurt is contributed by both casein and gelatin.

Subsequent research from quantitative descriptive analysis (QDA) of fish and pork gelatin suggested that fish gelatin has less offodor, faster rate of melt and can boost aroma release (Choi and Regenstein, 2000). In this respect, it is likely that fish gelatin also can be used as a gel enhancer in yoghurt products.

All in all, the gelling properties of yoghurt essentially contributed by milk protein network. The interactions of protein with other compounds, which is released during fermentation of yoghurt (i.e. lactic acid), and added to the yoghurt process (i.e. stabilizers gelatin) also characterized the gel network. 


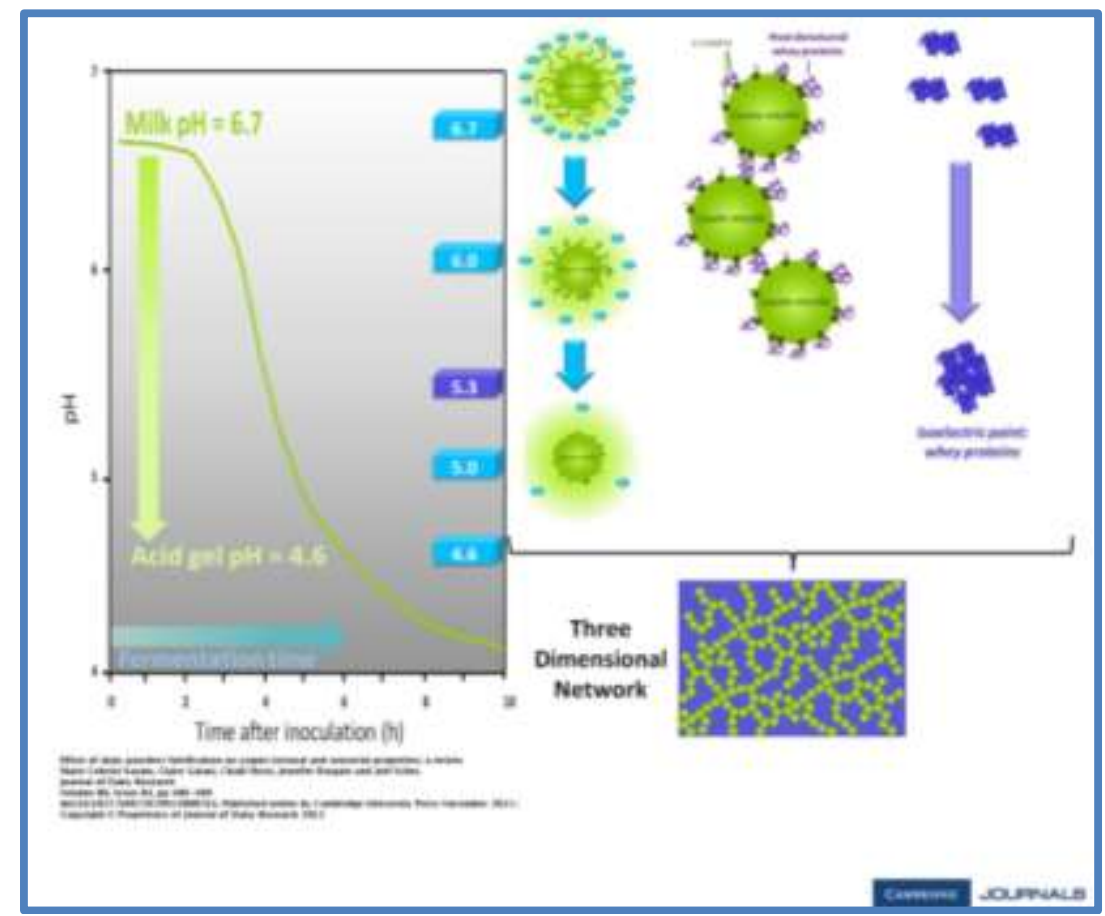

Figure 1. Typical $\mathrm{pH}$ profiles during the fermentation process of yoghurt Source: Karam et al.(2013)

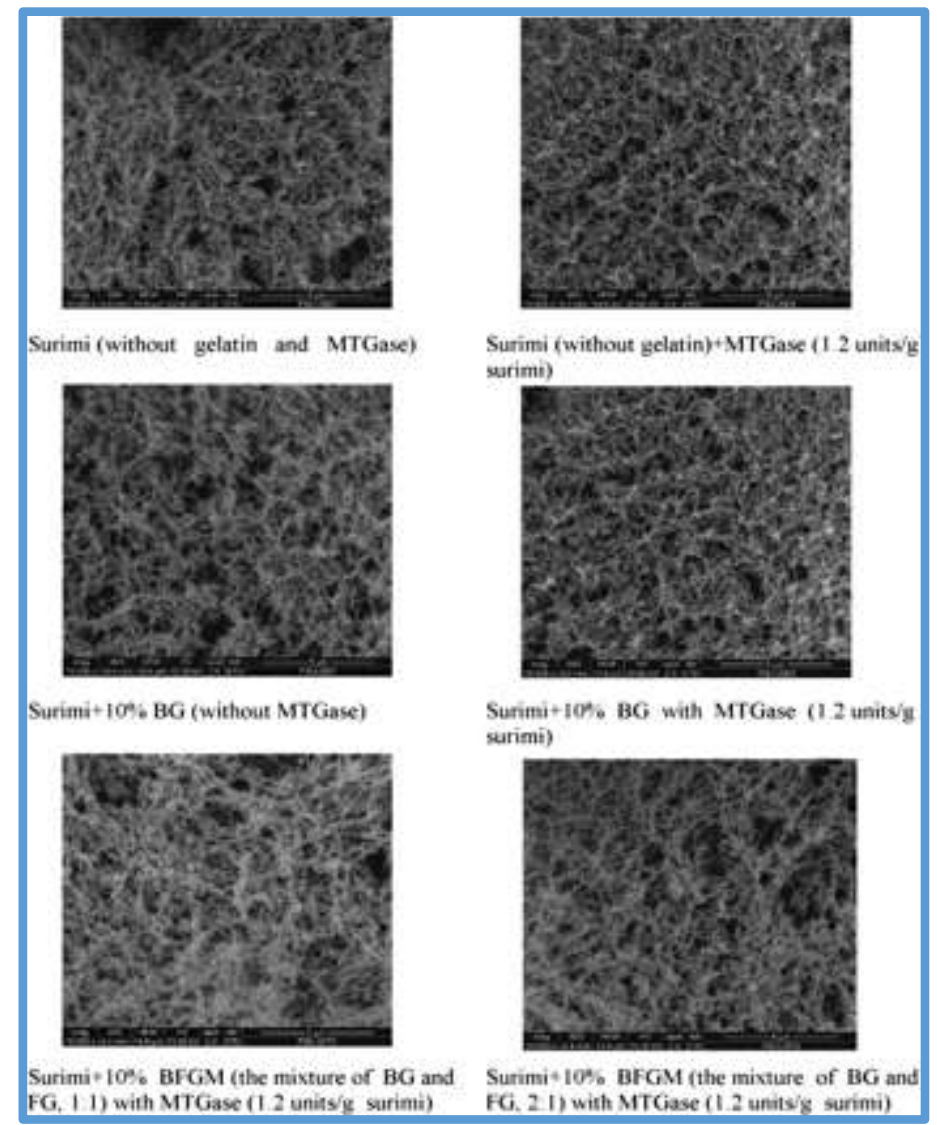

Figure 2. Electron microscopic images of surimi gel from threadfin bream added with $10 \%$ BF or BFGM. Without and with MTGase 1.2 units/g surimi (magnification is $\times 10,000$ ) Source: Kaewodum et al.(2012) 


\section{Surimi}

Surimi can be defined as "deboned, minced, and washed fish flesh" (Martin-Martin-Sanchez et al., 2009). A gel in surimi dominantly contributed by myofibrillar protein. The networking between protein connected by ionic linkages, hydrogen bonds, hydrophobic bonds, and covalent bonds in the heating process. Salt added to the surimi will solubilized myosin and actin muscle protein in fish. The continuous matrix of hydrophilic protein and low molecular weight particles perform the gel. Twice heating process will develop the gelling characteristics of surimi. According to Martin-Sanchez et al. (2009) there are two critical thermal of surimi gelation mechanism. First, setting process (suwari), material should be heated higher than $40^{\circ} \mathrm{C}$ for 2 to 4 hours or heated at lower temperature $\left(0-40^{\circ} \mathrm{C}\right)$ for 12 to 24 hours. The objective of this step is to improve protein network and strengthens gel texture. Next, after setting, the suwari gel is cooked at 80 to $90^{\circ} \mathrm{C}$ so that it will change into a rigid and irreversible gel. Texture, especially gel strength is usually used to grade surimi since it will affect the quality and price (Hu et al., 2007 cited by Martin-Sanchez et al., 2009).

Major factor contributing to surimi gel processing is the freshness of the raw material. High quality of raw material will affect gelation properties of surimi and the water holding capacity (Martin-Sanchez et al., 2009). To achieve fresh raw material, it requires shorter postmortem time, so that the myofibrillar proteins, glycogen content, and muscle $\mathrm{pH}$ still remain stable. In other words, we have to maintain a slower rate of proteolysis so that we can achieve high grade of surimi. Thus, it is suggested that ideal processing time of surimi is after $12 \mathrm{~h}$ of harvesting (Martin-Sanchez et al., 2009).

Raw material (fish) could be stored longer than $12 \mathrm{~h}$, either on chilling or freezing temperature. Toyoda et al. (1992) reported that during $5^{\circ} \mathrm{C}$ storage of fish, the gel strength will drop quickly in just a few days (cited in MartinSanchez et al. 2009). In frozen storage, oxidation of myofibrillar proteins can modify protein networking, decrease $\mathrm{Ca}^{2+}$ ATPase, and affects gel-forming ability (Martin-Sanchez et al.2009). Surimi made from frozen fish can loss cohesiveness since the myofibrillar proteins will denature and aggregate during frozen storage. Benjakul et al. (2005) then proposed that reducing agents such as cysteine can be used to improve the gel quality of surimi from frozen fish. The addition of cysteine can reduce the disulfide bonds and increase the sulfhydryl content. It can re-naturate myosin molecule by increasing $\mathrm{Ca}^{2+}$ ATPase and activated transglutaminase of fish muscle; thus, it increased gel-forming ability and develop cohesiveness of surimi.

Additionally, commercial gelatin can be used in meat products as it can provide water binding capacity. Hernandez-Briones et al. (2009) works showed that adding $7.5 \mathrm{~g} / \mathrm{kg}$ commercial fish gelatin to Alaska Pollock surimi grade A improved its water holding capacity and gel strength, but it did not affect Alaska Pollock surimi grade FA. On the contrary, fish gelatin concentration higher than $10 \mathrm{~g} / \mathrm{kg}$ will disrupt the gelling system mechanical properties. Originally, Alaska Pollock surimi grade FA have higher mechanical properties of gels than surimi grade A, that is why they suggested that fish gelatin might be used as a functional additive to produce Alaska surimi gels but, it is not suitable for the grade FA.

Another finding from Kaewudom et al. (2012) concluded that mixtures of bovine and fish gelatin with ratio $1: 1$ or $1: 2$, respectively and with the addition of 1.2 units/g microbial transglutaminase can enhance the gel properties of threadfin bream surimi. Figure 2 showed the electron microscopic images of surimi gels at different treatment. Surimi gel network become finer, with the addition of MTGase as compared with control gel. On the contrary, the structure of surimi in the presence of $10 \%$ bovine gelatin (BG) or bovine fish gelatin mixed (BFGM) become rougher even with the addition of MTGase. It is likely that adding gelatin showed no positive impact to surimi microstructure.

Overall, the gelling properties of surimi mainly contributed by muscle protein of fish. The addition of gelatin either from mammalian or fish or mixed of fish and bovine gelatin in appropriate concentration can improve the water binding capacity and gel strength. Supplement transglutaminase also can strengthen the network of surimi gel. 


\section{CONCLUSION}

Gelatin can be used in various food system. The mechanism of gelation mainly contributed by the networking of protein-protein. The intermolecular bond and intramolecular bond help strengthen the networking of protein. Gel characteristics of gelatin water gel dessert are affected by gelatin source (fish or mammalian), gelatin concentration, and other ingredients $(\mathrm{NaCl}$ and sucrose). Casein network and casein re-arrangement with other compounds (i.e lactic acid, gelatin) during yoghurt processing essentially contributing to yoghurt texture. Myosin and actin in fish muscle predominantly form surimi. Water binding capacity and gel strength of surimi can be enhanced by gelatin in proper concentration. This review shows that despite the fact that mammalian gelatin did not preferable for vegetarian, kosher, and halal market, it really useful for a variety of food products. Future research of gelatin based on fisheries by-product or by-catch as an alternative to substitute mammalian gelatin should be performed. Thus, the controversy issues of the used of gelatin could be reduced. Moreover, from the environmental perspective, utilize fishery by-products or by-catch should be considered as an aid to shrink waste from fishery processing and catching. However, it should be noted that the quality on fish gelatin usually varies depend of its intrinsic factor, such as species, age, and gender, and also extrinsic characteristics such as water environment (tropical or cold water), fishing methods, batch of harvest, and storage time. Hence, creation of gelling properties of gelatin combines with other plant-based hydrocolloids should be considered beneficial to the product developers.

\section{REFERENCES}

Ares G, Goncalvez D, Perez C, Reolon G, Segura N, Lema P, Gambaro A. 2007. Influence of gelatin and starch on the instrumental and sensory texture of stirred yoghurt. Inter J Dairy Tech 60(4): 262-9.
Benjakul S, Thongkaew C, Visessanguan W. 2005. Effect of reducing agents on physicochemical properties and gel-forming ability of surimi produced from frozen fish. Eur Food Res Technol 220: 316-21.

Choi SS, Regenstein JM. 2000. Physicochemical and Sensory Characteristics of Fish Gelatin. J Food Sci 65(2): 194-9.

Djagny KB, Wang Z, Xu S. 2010. Gelatin: A valuable protein for food and pharmaceutical industries: Review. Crit Rev Food Sci 41(6): 481-92

Hernandez-Briones A, Velazquez G, Vazquez M, Ramirez JA. 2009. Effect of adding fish gelatin on Alaska Pollock surimi gels. Food Hydrocolloid 23: 2446-9.

Kaewudom P, Benjakul S, Kijroongrojana K. 2012. Effect of bovine and fish gelatin in combination with microbial transglutaminase on gel properties of threadfin bream surimi. Inter Aquatic Res 4: 1-12.

Karam MC, Gaiani C, Hosri C, Burgain J, Scher J. 2013. Effect of dairy powders fortification on yoghurt textural and sensorial properties: a review. J Dairy Res 80: 400-9.

Karim AA, Bhat R. 2008. Gelatin alternatives for the food industry: recent developments, challenges and prospects. Trends Food Sci Tech 19: 644-56.

Lee WJ, Lucey JA. 2010. Formation and physical properties of yoghurt. Asian-Aust J Anim Sci 23(9): 1127-36.

Mariod AA, Adam HF. 2013. Review: Gelatin, Source, extraction and Industrial Application. Acta Sci. Pol. Technol. Aliment, 12(2), 135-47.

Martin-Sanchez AM, Navarro C, Perez-Alvarez JA, Kuri V. 2009. Alternatives for efficient and sustainable production of surimi: a review. Compr Rev Food Sci F 8: 359-74.

Ninan G, Zynudheen AA, Joseph J. 2011. Physicochemical and textural properties of gelatins and water gel desserts prepared from the skin of freshwater carps. Fishery Tech 48:67-74.

Pang Z, Deeth H, Sopade P, Sharma R, Bansal N. 2014. Rheology, texture and microstructure of gelatin gels with and without milk proteins. Food Hydrocolloid 35: $484-93$

Zhou P, Regenstein JM. 2007. Comparison of water gel desserts from fish skin and pork gelatins using instrumental measurements. J Food Sci 72(4): C196201.

Zhou P, Mulvaney SJ, Regenstein JM. 2006. Properties of Alaska Pollock skin gelatin extraction: a comparison with tilapia and pork skin gelatins. J Food Sci 71:C312-21. 